\title{
Radiation Exposure during Percutaneous Endoscopic Lumbar Discectomy: Interlaminar versus Transforaminal
}

\section{Exposição à radiação durante discectomia endoscópica lombar percutânea: interlaminar versus transforaminal}

\author{
Marcelo Campos Moraes Amato ${ }^{1}$ Bruno César Aprile ${ }^{1}$ Cezar Augusto de Oliveira ${ }^{1}$ \\ ${ }^{1}$ Amato Instituto de Medicina Avançada, São Paulo, SP, Brazil \\ Address for correspondence Marcelo Campos Moraes Amato, MD, PhD, \\ Arq Bras Neurocir 2019;38:31-35. \\ Amato Instituto de Medicina Avançada, Av. Brasil, 2283, Jardim América, \\ 01431-001, São Paulo, SP, Brazil (e-mail: marcelo@amato.com.br).
}

\begin{abstract}
Keywords

- intervertebral disc displacement

- fluoroscopy

- background radiation

- artroscopy
\end{abstract}

\section{Resumo}

Objective Percutaneous endoscopic lumbar discectomy (PELD) relies heavily on fluoroscopy guidance; therefore, medical staff exposure to radiation has become an important issue. The purpose of this study was to determine the radiation dose and the amount of time to which the surgeons are exposed during PELD and to compare both parameters in the transforaminal (TF) and interlaminar (IL) approaches. Although they are considerably different, they may be wrongly considered together.

Methods A retrospective evaluation of the last 20 PELD performed by the authors is presented. Patients were distributed in 2 groups. Six ( $1 \mathrm{~F}, 5 \mathrm{M})$ patients were submitted to IL-PELD and $14(6 \mathrm{~F}, 8 \mathrm{M})$ to TF-PELD. Fluoroscopy reports were obtained from patients' records, all performed with the same C-Arm device and software mode. Groups were compared using unpaired $t$-test.

Results The IL group showed an average radiation exposure of $8.37 \pm 4.21 \mathrm{mGy}$ and duration of $11.1 \pm 5.45$ seconds, while the TF group showed an average radiation exposure of $28.92 \pm 7.56 \mathrm{mGy}$ and duration of $42 \pm 16.64$ seconds. The $p$-value for radiation was 0.0000036 , and for time it was 0.00027 .

Conclusions Interlaminar PELD requires a lower radiation dose and a shorter amount of exposure than TF-PELD. Studies that concern radiation required for minimallyinvasive spine surgeries should consider the PELD approaches separately.

Objetivo A discectomia endoscópica lombar percutânea (DELP) depende muito de orientação por fluoroscopia; portanto, a exposição à radiação se tornou um assunto importante. O objetivo deste estudo foi determinar a dose e o tempo de radiação aos quais os cirurgiões estão expostos durante a discectomia endoscópica lombar percutânea (DELP) e comparar ambos os parâmetros nos acessos transforaminal (TF) e interlaminar (IL). Embora sejam consideravelmente diferentes, estes podem ser erroneamente considerados em conjunto.

Métodos Avaliação retrospectiva dos últimos 20 casos de DELP realizados pelos autores. Os paciente foram distribuídos em dois grupos. Seis $(1 \mathrm{M}, 5 \mathrm{H})$ pacientes foram submetidos a DELP-IL e 14 (6M, 8H) a DELP-TF. Os dados da fluoroscopia foram obtidos received

May 24, 2018

accepted

January 8, 2019

published online

February 6, 2019
DOI https://doi.org/

10.1055/s-0039-1677883. ISSN 0103-5355.
Copyright (e 2019 by Thieme Revinter

Publicações Ltda, Rio de Janeiro, Brazil
License terms

(ㄷ) (i) $\ominus$ (\$) 


\begin{tabular}{|c|c|}
\hline & $\begin{array}{l}\text { dos relatórios dos pacientes, todos avaliados usando o mesmo aparelho de arco } \\
\text { cirúrgico e no mesmo modo do programa. Os grupos foram comparados utilizando o } \\
\text { teste- } t \text { não pareado. }\end{array}$ \\
\hline $\begin{array}{l}\text { Palavras-chave } \\
\text { - deslocamento do disco } \\
\text { intervertebral }\end{array}$ & $\begin{array}{l}\text { Resultados } \mathrm{O} \text { grupo IL mostrou exposição média à radiação de } 8,37 \pm 4,21 \text { mGy e } \\
\text { duração de } 11,1 \pm 5,45 \text { segundos, enquanto o grupo TF apresentou exposição média à } \\
\text { radiação de } 28,92 \pm 7,56 \text { mGy e duração de } 42 \pm 16.64 \text { segundos. O valor de p para a } \\
\text { radiação foi de } 0.0000036 \text { e para o tempo foi de } 0.00027 \text {. }\end{array}$ \\
\hline - fluoroscopia & Conclusões A DELP-IL necessita de menor quantidade de radiação e tempo do que a \\
\hline $\begin{array}{l}\text { - radiação de fundo } \\
\text { - artroscopia }\end{array}$ & $\begin{array}{l}\text { DELP-TF. Estudos cujo interesse é a radiação para cirurgias minimamente invasivas da } \\
\text { coluna devem considerar os diferentes acessos para DELP separadamente. }\end{array}$ \\
\hline
\end{tabular}

\section{Introduction}

Lumbar discectomy has traditionally been performed through microdiscectomy, an open surgical technique. Refinement of operative techniques, a better understanding of the anatomy, and the development of novel technology has led to less invasive surgical options, such as percutaneous endoscopic lumbar discectomy (PELD). Several trials have demonstrated the effectiveness of PELD; however, minimally invasive spine surgeries (MISS) such as PELD rely heavily on intraoperative navigation, and fluoroscopy guidance is usually chosen for a safe percutaneous approach and accurate localization. ${ }^{1-5}$ Therefore, medical staff exposure to radiation has become an important issue. ${ }^{1,6-8}$ Some publications have addressed the amount of radiation exposure in various percutaneous spine procedures, ${ }^{2,9-12}$ including PELD, ${ }^{1}$ but none have compared the amount of radiation in transforaminal (TF) and interlaminar (IL) approaches. Although the approaches are considerably different, they may be wrongly considered together when the topics are radiation exposure and PELD.

This study was performed considering the hypothesis that the IL-PELD uses a considerably lower amount of radiation, and that this would constitute an advantage over the TF-PELD. The purpose of this study was to determine the radiation dose and the amount of time to which the surgeons are exposed during PELD using a particular C-Arm device (Ziehm Solo, Ziehm Imaging, Nürnberg, Germany) and to compare both parameters in the TF and IL approaches.

\section{Methods}

\section{Surgical Technique Details}

Transforaminal PELD was typically performed as described previously ${ }^{1,13,14}$ and consisted of 2 parts: a TF approach under fluoroscopic control followed by selective discectomy with endoscopic visualization. The first part consists of insertion of the needle into the disc (-Fig. 1A), injection of contrast and methylene blue ( - Fig. 1B), then, the needle is replaced with a guide wire, and an obturator is introduced along the guide wire (-Fig. 1C). After the obturator position is confirmed, a bevelended working sheath is placed near the disc-herniation (-Fig. 1D-E). For safe introduction of the spinal needle, obturator and working sheath through the foraminal window, a real-time anteroposterior (AP) and/or lateral view in the $\mathrm{C}$ Arm device is essential. After insertion of the endoscope, the first part of the procedure is over, as well as the mainly use of fluoroscopy. Surgery is now performed under direct endoscopic visualization for discectomy using mainly forceps and radiofrequency coagulation. In this second part, fluoroscopy is used only seldom to check the position of the instruments and double check anatomic parameters (-Fig. 1F).

Interlaminar PELD also consisted of 2 parts. However, in this case, the first part, the fluoroscopic guided IL approach, is typically faster than the in the TF approach. While the TF approach is initiated with the insertion of a needle, in the IL approach, the obturator can be directly inserted after IL window identification in the AP view (-Fig. 2A) and a 1-cm skin incision, without the use of a needle. Lateral view is used to check the position and direction of the obturator, and the working sheath is then inserted, completing the first part of the procedure (-Fig. 2B). Surgery is then performed under direct endoscopic visualization for discectomy using mainly scissors, forceps, dissectors and radiofrequency coagulation. In this second part, fluoroscopy is used only seldom to check the position of the instruments and double check anatomic parameters (- Fig. 2C).

\section{Study Design and Sample}

The last 20 patients of this Institution that underwent PELD between May and December 2017, performed by the authors, were included in this retrospective study. Only those patients that underwent single-level, unilateral endoscopic decompression were included. No cases of decompressions adjacent to a fusion were included, and neither were those who needed foraminal or central stenosis treatment. Patients who did not have radiological data and archive were excluded. All data were acquired from the same C-Arm device (Ziehm Solo, Ziehm Imaging, Nürnberg, Germany) and performed in the same software mode. Surgeries performed with other devices or modes were not included. The surgeons had, at the time of the study, more than 6 years of endoscopic spine surgery experience.

\section{Results}

Six patients underwent IL-PELD, 1 female and 5 male, and 14 patients underwent TF-PELD, 6 female and 8 male (-Table $\mathbf{1}$ ). 


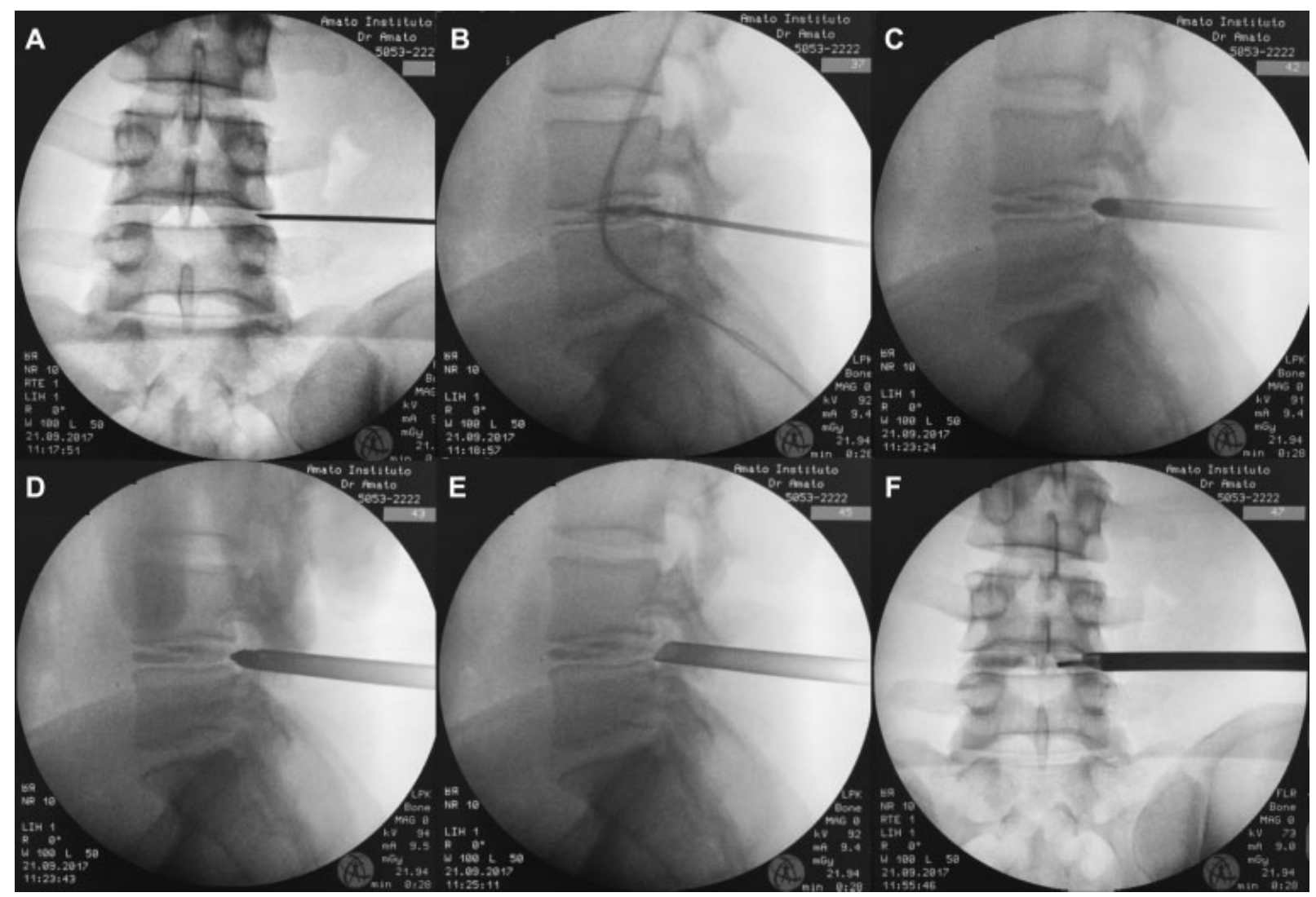

Fig. 1 Transforaminal percutaneous endoscopic discectomy. Fluoroscopic anteroposterior view (A) shows needle insertion into the disc. Lateral view (B) shows discography with contrast injection, then, obturator insertion (C), followed by working sheet insertion (D) and obturator withdraw. Anteroposterior view (F) shows working instrument inside the disc. Fluoroscopic data of patient number 6 are also displayed.

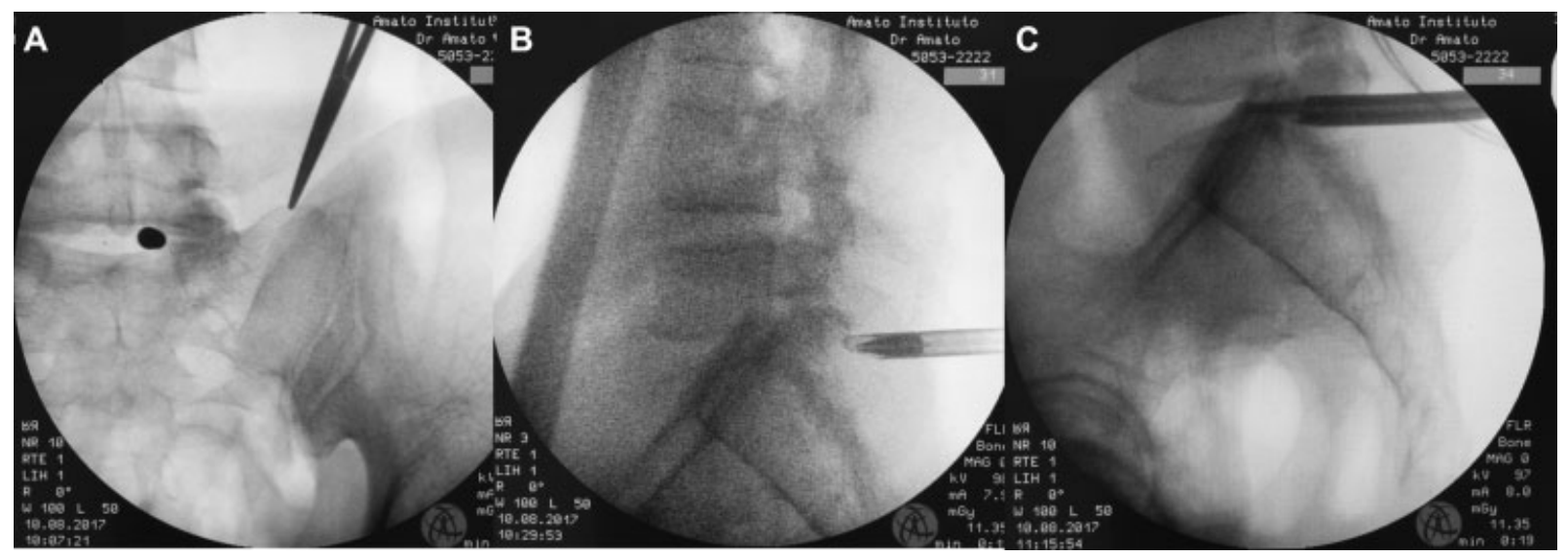

Fig. 2 Interlaminar percutaneous endoscopic discectomy. fluoroscopic anteroposterior view (A) shows direct insertion of the obturator. Lateral view (B) shows insertion of the working sheet. (C) shows working sheet and endoscope inside the spinal canal and a working instrument inside the disc. Fluoroscopic data of patient number 4 are also displayed.

The mean age of the patients was 46 years in IL-PELD and 46.8 years in IL-PELD. The average time of fluoroscopy was $11.2 \pm 5.5$ seconds in the IL group against $42.9 \pm 16.6$ in the TF group $(p=0.00027)$, and the amount of fluoroscopy exposure was $8.37+4.21 \mathrm{mGy}$ in the IL group against $28.92+7.56 \mathrm{mGy}$ in the TF group $(p=0.0000036)$ (-Table 2).

\section{Discussion}

Minimally invasive spine surgery and needle-based interventional spine procedures still typically depend on ionizing radiation for localization and guidance in placing the equipment, ${ }^{15}$ although different strategies have been adopted to reduce medical staff and patient exposure to radiation as 
34 Radiation Exposure during Percutaneous Endoscopic Amato et al.

Table 1 Individual characteristics and results of the 20 patients

\begin{tabular}{|c|c|c|c|c|c|c|}
\hline $\mathrm{N}$ & Age & G & Approach & Level and characteristics & Time (sec) & Radiation (mGy) \\
\hline 1 & 55 & $\mathrm{~F}$ & TF & L3L4 - foraminal - extrusion & $00: 48$ & 28.036 \\
\hline 2 & 51 & $\mathrm{M}$ & TF & L5S1 - foraminal - extrusion & $00: 40$ & 29.350 \\
\hline 3 & 71 & $\mathrm{M}$ & TF & L4L5 - posterolateral - extrusion & $00: 45$ & 35.296 \\
\hline 4 & 35 & $\mathrm{M}$ & $\mathrm{IL}$ & L5S1 - posterolateral - extrusion & $00: 19$ & 11.352 \\
\hline 5 & 40 & $\mathrm{~F}$ & TF & L1L2 - central - extrusion & $00: 59$ & 40.704 \\
\hline 6 & 30 & $\mathrm{M}$ & TF & L4L5 - posterolateral - extrusion & $00: 28$ & 21.939 \\
\hline 7 & 63 & $\mathrm{M}$ & TF & L4L5 - posterolateral - protrusion & $00: 44$ & 37.110 \\
\hline 8 & 54 & $\mathrm{M}$ & TF & L4L5 - posterolateral - down migration & $00: 34$ & 23.871 \\
\hline 9 & 42 & M & TF & L4L5 - posterolateral - down migration & $00: 23$ & 15.254 \\
\hline 10 & 41 & $\mathrm{M}$ & $\mathrm{IL}$ & L5S1 - posterolateral - extrusion & 00:09 & 4.236 \\
\hline 11 & 59 & $\mathrm{M}$ & TF & L4L5 - posterolateral - extrusion & $00: 34$ & 17.308 \\
\hline 12 & 41 & $\mathrm{~F}$ & TF & L5S1 - central - extrusion & $00: 50$ & 25.510 \\
\hline 13 & 41 & $\mathrm{~F}$ & TF & L4L5 - central - extrusion & $01: 30$ & 30.400 \\
\hline 14 & 38 & $\mathrm{M}$ & $\mathrm{IL}$ & L4L5 - posterolateral - down migration & 00:09 & 13.860 \\
\hline 15 & 72 & $\mathrm{M}$ & $\mathrm{IL}$ & L5S1 - central - extrusion & $00: 06$ & 5.115 \\
\hline 16 & 32 & $\mathrm{M}$ & TF & L4L5 - posterolateral - extrusion & $00: 42$ & 31.963 \\
\hline 17 & 39 & $\mathrm{~F}$ & TF & L4L5 - posterolateral - extrusion & $00: 35$ & 37.490 \\
\hline 18 & 37 & $\mathrm{~F}$ & TF & L5S1 - foraminal - extrusion & $00: 29$ & 30.620 \\
\hline 19 & 49 & $\mathrm{~F}$ & $\mathrm{IL}$ & L5S1 - posterolateral - extrusion & $00: 17$ & 11.079 \\
\hline 20 & 41 & $\mathrm{M}$ & $\mathrm{IL}$ & L5S1 - posterolateral - extrusion & 00:07 & 4.566 \\
\hline
\end{tabular}

Abbreviations: F, female; G, gender; IL, interlaminar; M, male; mGy, miligray; n, number; sec, seconds; TF, transforaminal.

Table 2 Statistical analysis

\begin{tabular}{|l|l|l|l|l|}
\hline & Time - IL (sec) & Time - TF (sec) & Radiation - IL (mGy) & Radiation TF (mGy) \\
\hline Average & 11.2 & 42.9 & 8.37 & 28.92 \\
\hline SD & 5.5 & 16.6 & 4.21 & 7.56 \\
\hline$p$-value & 0.0003 & 0.000004 & \\
\hline
\end{tabular}

Abbreviations: IL, interlaminar; mGy, miligray; SD, standard deviation; sec, seconds; TF, transforaminal.

well as to reduce operating time, such as ultrasound-assisted TF-PELD ${ }^{16}$ and preoperative location methods. ${ }^{17}$

It is known that among various discectomy techniques, the radiation dose is greater on PELD and other MISS when compared with open surgery. ${ }^{1,2}$ That is understandable, since fluoroscopy is used to help on anatomical identification throughout the non-open surgeries. Mariscalco et al also show that tubular microdiscectomy uses smaller doses of radiation than TF-PELD. ${ }^{2}$ The present work was able to show that there are differences among the PELD techniques.

Iprenburg et al state that the radiation doses required for TF-PELD are small and should not be enough to discourage patients from considering endoscopic spine surgery. They also state that L5-S1 PELD are significantly longer in duration than PELD at other lumbar levels and require a longer fluoroscopy period of exposure. ${ }^{15}$ The present work did not consider L5-S1 PELD in a different group, since we believe that difficult and longer cases of TF L5S1 discectomies might be due to lack of anatomical and disease considerations that should favor the IL approach instead. There were 3 patients submitted to TF-PELD for L5S1 disc herniations, for whom the time and amount of radiation were among the whole group average (Pts 2, 12 and 18 on - Table 1). On the other hand, Choi et al, in a multi-center study, reported no significant difference of the radiological features between the iliac crest and L5S1 disc space in two similar groups submitted either to TF or IL-PELD. Meaning that the surgical team used to perform the TF-PELD had similar patient characteristics when compared with the patients of the surgical team used to perform IL-PELD. ${ }^{18,19}$ Nevertheless, high iliac crest, large transverse process, high upward migration and axillary type disc herniation are still challenging for L5S1 TF-PELD. ${ }^{18}$ In regard to fluoroscopy, if TF-PELD is attempted in those cases, the amount of time and radiation exposure would certainly be higher. Along with other advantages, particularly in patients with wide interlaminar window, IL-PELD should be preferred. 
Choosing the better approach for each patient, considering not only the surgeons preference ${ }^{18}$ but the disease and anatomic particularities, may influence the amount of radiation exposure. While for some groups, L4L5 disc herniations may be considered for a TF-PELD approach only, the above-mentioned considerations should allow for a different approach. ${ }^{20}$ Indeed, patient n14 of this group had an L4L5 posterolateral disc herniation and due to a wide L4L5 interlaminar window, whereas hypertrophic facets, was submitted to IL-PELD and needed an average amount of fluoroscopy ( 9 seconds and $13.86 \mathrm{mGy}$ ).

\section{Conclusion}

Interlaminar PELD requires a smaller amount and less time of radiation exposure than TF-PELD. Studies that concern radiation required for MISS should consider the PELD approaches separately.

\section{Conflicts of Interest}

The authors have no conflicts of interest to report.

\section{References}

1 Ahn Y, Kim CH, Lee JH, Lee SH, Kim JS. Radiation exposure to the surgeon during percutaneous endoscopic lumbar discectomy: a prospective study. Spine 2013;38(07):617-625. Doi: 10.1097/ BRS.0b013e318275ca58

2 Mariscalco MW, Yamashita T, Steinmetz MP, Krishnaney AA, Lieberman IH, Mroz TE. Radiation exposure to the surgeon during open lumbar microdiscectomy and minimally invasive microdiscectomy: a prospective, controlled trial. Spine 2011;36(03): 255-260. Doi: 10.1097/BRS.0b013e3181ceb976

3 Mayer HM, Brock M. Percutaneous endoscopic discectomy: surgical technique and preliminary results compared to microsurgical discectomy. J Neurosurg 1993;78(02):216-225. Doi: 10.3171/ jns.1993.78.2.0216

4 Hoogland T, Schubert M, Miklitz B, Ramirez A. Transforaminal posterolateral endoscopic discectomy with or without the combination of a low-dose chymopapain: a prospective randomized study in 280 consecutive cases. Spine 2006;31(24):E890-E897. Doi: 10.1097/01.brs.0000245955.22358.3a

5 Ruetten S, Komp M, Merk H, Godolias G. Full-endoscopic interlaminar and transforaminal lumbar discectomy versus conventional microsurgical technique: a prospective, randomized, controlled study. Spine 2008;33(09):931-939. Doi: 10.1097/BRS.0b013e31816c8af7

6 Carpenter LM, Swerdlow AJ, Fear NT. Mortality of doctors in different specialties: findings from a cohort of 20000 NHS hospital consultants. Occup Environ Med 1997;54(06):388-395
7 Berrington A, Darby SC, Weiss HA, Doll R. 100 years of observation on British radiologists: mortality from cancer and other causes 1897-1997. Br J Radiol 2001;74(882):507-519. Doi: 10.1259/ bjr.74.882.740507

8 Klein LW, Miller DL, Balter S, et al; Joint Inter-Society Task Force on Occupational Hazards in the Interventional Laboratory. Occupational health hazards in the interventional laboratory: time for a safer environment. Catheter Cardiovasc Interv 2009;73(03): 432-438. Doi: 10.1002/ccd.21801

9 Rampersaud YR, Foley KT, Shen AC, Williams S, Solomito M. Radiation exposure to the spine surgeon during fluoroscopically assisted pedicle screw insertion. Spine 2000;25(20):2637-2645

10 Harstall R, Heini PF, Mini RL, Orler R. Radiation exposure to the surgeon during fluoroscopically assisted percutaneous vertebroplasty: a prospective study. Spine 2005;30(16):1893-1898

11 Bindal RK, Glaze S, Ognoskie M, Tunner V, Malone R, Ghosh S. Surgeon and patient radiation exposure in minimally invasive transforaminal lumbar interbody fusion. J Neurosurg Spine 2008; 9(06):570-573. Doi: 10.3171/SPI.2008.4.08182

12 Kim CW, Lee YP, Taylor W, Oygar A, Kim WK. Use of navigationassisted fluoroscopy to decrease radiation exposure during minimally invasive spine surgery. Spine J 2008;8(04):584-590. Doi: 10.1016/j.spinee.2006.12.012

13 Yeung AT, Tsou PM. Posterolateral endoscopic excision for lumbar disc herniation: Surgical technique, outcome, and complications in 307 consecutive cases. Spine 2002;27(07):722-731

14 Ahn Y, Lee SH, Park WM, Lee HY, Shin SW, Kang HY. Percutaneous endoscopic lumbar discectomy for recurrent disc herniation: surgical technique, outcome, and prognostic factors of 43 consecutive cases. Spine 2004;29(16):E326-E332

15 Iprenburg M, Wagner R, Godschalx A, Telfeian AE. Patient radiation exposure during transforaminal lumbar endoscopic spine surgery: a prospective study. Neurosurg Focus 2016;40(02):E7. Doi: 10.3171/2015.11.FOCUS15485

$16 \mathrm{Wu}$, Liao X, Xia H. Radiation exposure to the surgeon during ultrasound-assisted transforaminal percutaneous endoscopic lumbar discectomy: A prospective study. World Neurosurg 2017;101:658-665.e1. Doi: 10.1016/j.wneu.2017.03.050

17 Fan G, Gu X, Liu Y, et al. Lower learning difficulty and fluoroscopy reduction of transforaminal percutaneous endoscopic lumbar discectomy with an accurate preoperative location method. Pain Physician 2016;19(08):E1123-E1134

18 Choi KC, Kim JS, Ryu KS, Kang BU, Ahn Y, Lee SH. Percutaneous endoscopic lumbar discectomy for L5-S1 disc herniation: transforaminal versus interlaminar approach. Pain Physician 2013;16 (06):547-556

19 Choi G, Lee SH, Lokhande P, et al. Percutaneous endoscopic approach for highly migrated intracanal disc herniations by foraminoplastic technique using rigid working channel endoscope. Spine 2008;33 (15):E508-E515. Doi: 10.1097/BRS.0b013e31817bfa1a

20 Wang B, Lü G, Patel AA, Ren P, Cheng I. An evaluation of the learning curve for a complex surgical technique: the full endoscopic interlaminar approach for lumbar disc herniations. Spine J 2011;11(02):122-130. Doi: 10.1016/j.spinee.2010.12.006 